\title{
Efficiency of Post-Operative Pain Management in Infants undergoing Cleft Lip and Plate Repairs: A Study using the FLACC Scale
}

\author{
Saman Nanayakkara ${ }^{I^{*}}$, Indumathie Nanayakkara², Parakrama Wijekoon ${ }^{3}$, Yamuna R. Athukorala, \\ Piumi U. Nakandala ${ }^{5}$, Sithara Rathnayake ${ }^{6}$
}

${ }^{1}$ Senior Lecturer, Department of Anaesthesiology and Critical Care, ${ }^{2}$ Senior Lecturer, Department of Physiology, Faculty of Medicine, University of Peradeniya, ${ }^{3}$ Senior Lecturer, Department of OMF Surgery, Faculty of Dental Sciences, University of Peradeniya, ${ }^{4}$ Lecturer, Department of Nursing, Faculty of Allied Health Sciences, University of Peradeniya, ${ }^{5}$ Physiotherapist, National Hospital, Kandy ${ }^{6}$ Nursing Student, Department of Nursing, Faculty of Allied Health Sciences, University of Peradeniya.

\begin{abstract}
Background
Post-operative pain relief in cleft surgery should be efficient and effective. The Face, Leg, Activity, Cry and Consolability (FLACC) scale is a validated tool for post-operative pain assessment in patients who cannot express themselves verbally. The objective of this study was to assess the effectiveness of the analgesic protocol practiced at the Dental Hospital Peradeniya, using FLACC scale during the first 24 hours following cleft surgery.
\end{abstract}

\section{Methods and material}

Sample included 193 patients who underwent primary repair of cleft lip and palate. They were given paracetamol two hours before surgery and $0.1 \mathrm{mg} / \mathrm{kg}$ intravenous morphine during surgery. Infra-orbital nerve blocks for cleft lip surgeries, greater palatine nerve blocks for cleft palate surgeries and rectal diclofenac suppository $(1.5 \mathrm{mg} / \mathrm{kg})$ if above six months of age were added. The surgical site was infiltrated with $1 \%$ lignocaine in adrenaline. Oral paracetamol was used post-operatively. Cuddling, carrying, lullaby singing and nursing by mother was used as nonpharmacological strategies in the ward. Pain assessment was done at 5 min after recovery from anaesthesia and then at 30 minutes, 1 hour, 1.5 hours, 2 hours, 2.5 hours, 3 hours, 3.5 hours, 4 hours, 5 hours and 6 hours after recovery, and then at 8 am and 12 noon on the day following surgery using the FLACC scale.

\section{Results}

The number of patients with severe to profound pain reduced gradually following recovery, except for a minor resurgence of pain at 2.5 hours. At the end of first 24 hours, $92.7 \%$ of patients had no pain according to the FLACC scale while only less than $1 \%$ had severe pain.

\section{Conclusion}

The combined protocol of pharmacological and non-pharmacological strategies used at the Cleft Centre was highly effective for relief of post-operative pain in cleft surgeries.

Key words: infants, cleft-lip, cleft-palate, diclofenac, paracetamol, morphine, pain

\section{Introduction}

Post-operative pain is an invariable experience

*Correspondence: Saman Nanayakkara

E mail: nsaman@y7mail.com

https://orcid.org/0000-0001-7832-9621

Received: $28 / 07 / 2020$

Accepted: 07/01/2021

DOI: http:/doi.org/10.4038/slja.v29i1.8646

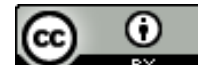

associated with surgeries. Infants are unable to self-report the existence, location and intensity of pain. Moreover, prolonged exposure to pain results in consequences such as worsening of stress response and delayed recovery from illness. ${ }^{1}$ Therefore, clinicians need to manage postoperative pain effectively. Many pharmacological and nonpharmacological measures are used for controlling post-operative pain. Drug therapy includes paracetamol (acetaminophen), ibuprofen, diclofenac, morphine, pethidine and fentanyl. 
Non-pharmacological strategies in infants include cuddling and keeping the baby warm, singing lullabies, patting and verbal reassurance from the mother. $^{2}$

Cleft deformities are considered the most common craniofacial abnormality ${ }^{3}$, with the incidence being 1 in 600 to 700 live births in the world and cleft palate alone being 1in 2000 live births ${ }^{4}$.In Sri Lanka, cleft abnormalities occur at a rate of 0.83 per 1000 live births. ${ }^{5}$ Generally, cheiloplasty (cleft lip repair) and palatoplasty (cleft palate repair) are carried out at 4-5 months and 9-12 months respectively. ${ }^{6}$ However, the success of treatment depends on patient, surgical and anaesthetic factors including post-operative care.

Many scales have been used to assess pain in those who cannot express verbally. Behavioral Pain Scale (BPS), checklist of non-verbal pain indicators, Critical care Pain Observation Tool (CPOT), Multidimensional Observational Pain Assessment Tool (MOPAT), Nociceptive coma scale, Children's Hospital of Eastern Ontario Pain Scale (CHEOPS), Visual Analog Scale (VAS), FLACC (Face, Legs, Activity, Consolability $\&$ Cry) and COMFORT scale are some of them.

FLACC scale has been identified as a validated and reliable tool to assess the degree of pain in pediatric patients. ${ }^{7}$ This can be applied with accuracy from 2 months to 8 years. ${ }^{8}$ The scale consists of five elements which include observation of Face, Legs, Activities, Cry and Consolability. Each element is marked from 0 to 2, which is summed up later to gain a total pain score ranging from 0 to 10 . The FLACC pain scale records 0 as absence of pain, 1-2 as mild pain, 3-4 as moderate pain, 5-6 as severe pain and 7-10 as profound pain.

The objective of the present study is to assess the effectiveness of the analgesic protocol being practiced at the Cleft Centre Peradeniya Sri Lanka, using FLACC scale during the first 24 hours after cleft surgeries (Cleft Lip Repair/cheiloplasty-CLR and Cleft Palate Repair/palatoplasty-CPR).

\section{Methodology}

This was an observational study which included all patients who underwent primary repair of cleft lip and palate over a nine-month period (01/2018 to 09/2018) at the Cleft Centre Peradeniya (Dental Hospital, Peradeniya). Syndromic patients and children with other medical problems (e.g.

Thalassemia) were excluded. Both pharmacological and non-pharmacological strategies of the analgesia protocol were practiced. Ethical approval was obtained from the ethics review committee of Faculty of Dental Sciences, University of Peradeniya. Informed written consent was obtained from all participating parents/ guardians.

All patients were given pre-emptive paracetamol $10 \mathrm{mg} / \mathrm{kg}$ two hours before surgery. During surgery each patient was given $0.1 \mathrm{mg} / \mathrm{kg}$ intravenous morphine on induction of general anaesthesia and at the end of surgery patients above the age of 6 months were given a rectal diclofenac sodium suppository $(1.5 \mathrm{mg} / \mathrm{kg})$ in addition. Induction and maintenance of anaesthesia was done with sevoflurane. Muscle relaxation for intubation was achieved with atracurium $0.5 \mathrm{mg} / \mathrm{kg}$ and was reversed with neostigmine \& atropine. An infraorbital nerve block was given for cleft lip surgeries and a greater palatine nerve block for cleft palate surgeries with $1 \%$ lignocaine (with 1 in 200,000 adrenaline). The same solution was infiltrated to the surgical site for vasoconstriction, reduction of bleeding and analgesia. In the postoperative stage, paracetamol $10 \mathrm{mg} / \mathrm{kg}$ was administered 8 hourly. Non-pharmacological strategies practiced were carrying the baby by the mother, cuddling, singing lullabies and bottle feeding when the baby started waking up in the recovery area of the operating theatre and in the post-operative ward.

Pain assessment was done by a single researcher. First assessment was done $5 \mathrm{~min}$ after recovery from anaesthesia in the operating theatre recovery area and then at 30 minutes, 1 hour, 1.5 hours, 2 hours, 2.5 hours, 3 hours, 3.5 hours, 4 hours, 5 hours and 6 hours after recovery, and then at 8 am and 12 noon on the day following surgery, in the post-operative ward using the FLACC scale. There was no intervention and the observer watched the pain-relief protocol being executed and assessed the FLACC scale. Pain intensity data were analyzed using Chi-square in Minitab 16 (Minitab Inc. USA). Percentages were calculated where relevant. 


\section{Results}

The sample included 193 patients who underwent cleft surgeries of which $41 \%$ were cheiloplasties. A slightly higher proportion of males were found among those who had cheiloplasties. Mean age was 4.4 months for patients undergoing cheiloplasty and 9.2 months for patients undergoing palatoplasty $(\mathrm{p}<0.001)$.

At five minutes following recovery, $93 \%$ of the patients were found to have severe to profound pain irrespective of the type of surgery (Figure 1 \& Table 1).

However, by 30 minutes, $56 \%$ had no pain at all while only $6 \%$ had profound to severe pain. At two hours, the intensity of post-operative pain had reduced further where $71 \%$ were pain free while only $4 \%$ had severe to profound pain. But, a steady increase in the number of patients with severe to profound pain was apparent at 2.5 hours. Accordingly, there was a resurgence of severe to profound pain in 18\% while leaving only $38 \%$ patients free of pain at 2.5 hours (Figure $1 \&$ Table 1).
At six hours post-op, the pain control was highly satisfactory with $81 \%$ having no pain at all and only $4 \%$ of the sample having severe pain. At the end of first 24 hours, $91 \%$ of patients had no pain according to FLACC scale while only $1 \%$ had severe pain. There was no difference in the pain relief between cheiloplasties and palatoplasties (Table 2, p>0.05) at $30 \mathrm{~min}, 2.5$ hours and 6 hours post-op.

\section{Discussion}

An attempt was made to assess the effectiveness of the analgesic protocol practiced at the Cleft Center, Peradeniya using FLACC scale. The protocol involved, pre-operative administration of paracetamol, intra-operative use of intravenous morphine, calculated for body weight of patient together with rectal diclofenac suppositories at the end of surgery if the child was above six months of age. These drugs were supplemented by infraorbital or greater palatine nerve blocks with lignocaine \& adrenaline solution, lignocaineadrenaline infiltration around the surgical site. Post-operatively paracetamol was administered

\section{Table 1}

Percentage of patients who had pain according to the FLACC scale in the total sample at different times postop

\begin{tabular}{|c|c|c|c|c|c|c|c|c|c|c|c|c|c|}
\hline \multirow[t]{2}{*}{$\begin{array}{l}\text { FLACC } \\
\text { Score }\end{array}$} & \multicolumn{13}{|c|}{$\begin{array}{l}\text { Percentage of patients who had pain according to the FLACC scale in the total sample at } \\
\text { different times post-op }\end{array}$} \\
\hline & $\begin{array}{c}5 \\
\min \end{array}$ & $\begin{array}{c}30 \\
\min \end{array}$ & $\begin{array}{c}1 \\
\text { hrs }\end{array}$ & $\begin{array}{l}1.5 \\
\text { hrs }\end{array}$ & $\begin{array}{c}2 \\
\mathrm{hrs}\end{array}$ & $\begin{array}{l}2.5 \\
\text { hrs }\end{array}$ & $\begin{array}{c}3 \\
\text { hrs }\end{array}$ & $\begin{array}{l}3.5 \\
\text { hrs }\end{array}$ & $\begin{array}{c}4 \\
\text { hrs }\end{array}$ & $\begin{array}{c}5 \\
\text { hrs }\end{array}$ & $\begin{array}{c}6 \\
\text { hrs }\end{array}$ & $\begin{array}{c}8 \\
\text { am }\end{array}$ & $\begin{array}{c}12 \\
\text { noon }\end{array}$ \\
\hline 0 & 0 & 56 & 75 & 82 & 71 & 38 & 62 & 59 & 55 & 61 & 81 & 91 & 91 \\
\hline $1-2$ & 1 & 33 & 16 & 13 & 17 & 24 & 22 & 18 & 22 & 15 & 6 & 1 & 6 \\
\hline $3-4$ & 6 & 4 & 1 & 3 & 9 & 20 & 8 & 13 & 15 & 13 & 4 & 5 & 2 \\
\hline $5-6$ & 34 & 3 & 5 & 1 & 3 & 10 & 8 & 10 & 6 & 8 & 4 & 2 & 1 \\
\hline $7-10$ & 59 & 3 & 3 & 1 & 1 & 8 & 0 & 0 & 2 & 3 & 0 & 1 & 0 \\
\hline
\end{tabular}

Table 2

The association between the type of the surgery and the intensity of pain

\begin{tabular}{|c|c|c|c|c|c|c|}
\hline \multirow{3}{*}{$\begin{array}{l}\text { Intensity of the } \\
\text { pain/ FLACC scale }\end{array}$} & \multicolumn{6}{|c|}{ Number of patients (percentages within parenthesis) } \\
\hline & \multicolumn{2}{|c|}{$30 \mathrm{~min}$} & \multicolumn{2}{|c|}{2.5 hours } & \multicolumn{2}{|c|}{6 hours } \\
\hline & $\begin{array}{l}\text { Cheiloplasty } \\
\text { (CLR) }\end{array}$ & $\begin{array}{l}\text { Palatoplasty } \\
\text { (CPR) }\end{array}$ & $\begin{array}{l}\text { Cheiloplasty } \\
\text { (CLP) }\end{array}$ & $\begin{array}{l}\text { Palatoplasty } \\
\text { (CPR) }\end{array}$ & $\begin{array}{l}\text { Cheiloplasty } \\
\text { (CLR) }\end{array}$ & $\begin{array}{c}\text { Palatoplasty } \\
\text { (CPR) }\end{array}$ \\
\hline No pain $(0)$ & $\begin{array}{c}53 \\
66.25 \% \\
\end{array}$ & $\begin{array}{c}65 \\
57.52 \%\end{array}$ & $\begin{array}{c}29 \\
36.25 \%\end{array}$ & $\begin{array}{c}52 \\
46.01 \%\end{array}$ & $\begin{array}{c}73 \\
91.25 \%\end{array}$ & $\begin{array}{c}98 \\
86.72 \%\end{array}$ \\
\hline $\begin{array}{l}\text { Mild (1-2) to } \\
\text { Moderate (3-4) }\end{array}$ & $\begin{array}{c}23 \\
28.75 \% \\
\end{array}$ & $\begin{array}{c}39 \\
34.51 \% \\
\end{array}$ & $\begin{array}{c}41 \\
51.25 \% \\
\end{array}$ & $\begin{array}{c}42 \\
37.16 \% \\
\end{array}$ & $\begin{array}{c}6 \\
7.50 \% \\
\end{array}$ & $\begin{array}{c}10 \\
8.84 \% \\
\end{array}$ \\
\hline $\begin{array}{l}\text { Severe }(5-6) \text { to } \\
\text { Profound }(7-10)\end{array}$ & $\begin{array}{c}4 \\
5.00 \%\end{array}$ & $\begin{array}{c}9 \\
7.96 \%\end{array}$ & $\begin{array}{c}10 \\
12.50 \%\end{array}$ & $\begin{array}{c}19 \\
16.81 \%\end{array}$ & $\begin{array}{c}1 \\
1.25 \%\end{array}$ & $\begin{array}{c}5 \\
4.42 \%\end{array}$ \\
\hline $\mathrm{p}$ value & \multicolumn{2}{|c|}{0.432} & \multicolumn{2}{|c|}{0.149} & \multicolumn{2}{|c|}{0.421} \\
\hline Chi square & \multicolumn{2}{|c|}{1.68} & \multicolumn{2}{|c|}{3.81} & \multicolumn{2}{|c|}{1.73} \\
\hline
\end{tabular}


eight hourly together with non-pharmacological strategies by the mother which included cuddling, singing lullabies and bottle feeding by the mother.

FLACC scale has been validated and is considered reliable as a measure of pain in conscious preverbal children. ${ }^{9,10}$ It is reported to provide a simple framework for quantifying pain behaviors in children who may not be able to verbalize the preverbal children. ${ }^{9,10}$ It is reported to provide a presence or severity of pain. ${ }^{7}$ However, in addition to pain all criteria noted namely- facial expressions, leg raising, activity, consolability and cry could also be affected by distress, anger, hunger, thirst or irritability in general. This together with observer variability would be drawbacks of the FLACC scale. The interventions that were done during that first $30 \mathrm{~min}$ postoperative period in our study were letting the mother carry the baby, sing lullabies, cuddle and start bottle feeding. Without further analgesics upto the first two hours, the intensity of postoperative pain reduced gradually where $71 \%$ were pain free while only $4 \%$ had severe to profound pain, which means methods (pharmacological and non-pharmacological together) practiced before and during that period were effective in controlling either pain or general distress. Resurgence of severe to profound pain according to the FLACC scale, in $18 \%$ leaving only $38 \%$ patients free of pain at $2 \frac{1 / 2}{2}$ hours responded to the first dose of Paracetamol given around the same time. Paracetamol and diclofenac sodium given orally or rectally has been reported before as being very effective in cleft surgeries. ${ }^{11}$ There are reports in the literature stating that diclofenac combined with supplemental oral paracetamol, reduces the need for opiates, resulting in alert infants who feed well and could be discharged from hospital early. ${ }^{12}$

Babies in our study were started on oral feeds of milk within the first 30 minutes when they were fully awake and paracetamol was given 8 hourly. A large percentage of the infants showed a drastic reduction (CL \& CP 51\% \& 37\% became $7.5 \% 7$ $8.8 \%$ ) in the FLACC score when they were given Paracetamol syrup and the mother carried the child, cuddled, sang lullabies and bottle fed with milk. Therefore, it is not certain whether the higher FLACC score observed at $21 / 2$ hours postoperatively, reduced subsequently due to alleviation of pain by paracetamol or nonpharmacological management or the combination of both. However, the pain reduced rapidly after 6 hours. By the following day 12 noon $81 \%$ and $91 \%$ were free of pain according to FLACC scale.

Infiltration of the surgical site with lignocaine would also have helped in pain alleviation similar to what has been reported in the literature which used surgical site infiltration with bupivacaine. ${ }^{13}$ Infraorbital and greater palatine nerve blocks used by us, would have contributed for pain relief as previously reported by Takmaz et.al ${ }^{14}$ and Feriani et.al. ${ }^{15}$

Multimodal analgesia is always preferred as it reduces complications of individual modalities alone by reducing the dose and frequency of use. Our study also reiterates that analgesia protocols should be developed by individual institutes as reported by Reena et.al. depending on the type of surgery performed and the age of patients undergoing surgery. ${ }^{16}$

\section{Conclusion}

The combination of paracetamol, intravenous morphine, nerve blocks, lignocaine infiltration \pm rectal diclofenac sodium (the pharmacological strategies) and non-pharmacological strategies used in the present study were effective for relief of post-operative pain in cleft lip and palate surgery.

\section{References}

1. Kehlet H. Surgical stress: the role of pain and analgesia. British Journal of Anaesthesia. 1989; 63: $189-95$. https://doi.org/10.1093/bja/63.2.189 PMID: 2669908

2. Gehdoo RP. Post-operative pain management in paediatric patients. Indian Journal of Anaesthesia. 2004; 48: 406-14 https://doi.org/10.4103/ija.ija_696_19

3. Hujoel PP, Bollen AM, Mueller BA. First-year mortality among infants with facial clefts. The Cleft Palate- Craniofacial Journal.1992; 29: 451-5. https://doi.org./10.1597/1545$1569 \_1992 \_029 \_0451$ fymalw 2.3.co_2 PMID: 1472525

4. Mossey PA, Catilla EE. Global registry and database on craniofacial anomalies: Report of a WHO Registry Meeting on Craniofacial 
Anomalies. World Health Organization. Geneva, Switzerland. 2003

https://doi.org/10.1038/sj.bdj.4810738

PMID: 1472525

5. Amaratunga AN, Chandrasekara A. Incidence of cleft lip and palate in Sri Lanka. Journal of Oral \& Maxillo-facial Surgery. 1989; 47: 559- 61. https://doi.org/10.1016/S0278-2391(89)80066-7 PMID: 2723852

6. Chen PKT. Chang Gung Technique of Unilateral Cleft Lip Repair. In Cleft Lip and Palate Primary Repair. 2013; 105-158. Springer, Berlin, Heidelberg. https://doi.org/10.1007/978-3-642-38382-3 7

7. Merkel, S. I., Voepel-Lewis, T., Shayevitz, J. R., \& Malviya, S. (1997). The FLACC: a behavioral scale for scoring postoperative pain in young children. Pediatric Nursing, 23(3), 293-297

https://doi.org/10.1097/00000542-19940900101359

PMID: 9220806

8. Crellin DJ, Harrison D, Santamaria N, Babl FE. Systematic review of the Face, Legs, Activity, Cry and Consolability scale for assessing pain in infants and children: is it reliable, valid, and feasible for use? Pain. 2015; 156: 2132-51

https://doi.org/10.1097/j.pain.0000000000000305 PMID: 26207651

9. Malviya, S., Voepel-Lewis, T., Burke, C., Merkel, S., \& Tait, A. R. (2006). The revised FLACC observational pain tool: Improved reliability and validity for pain assessment in children with cognitive impairment. Paediatric Anaesthesia,16(3), 258-265 https://doi.org/10.1111/j.1460-9592.2005.01773.x PMID: 16490089

10. Manworren, R., \&Hynan, L. (2003). Clinical validation of FLACC: Preverbal patient pain scale. $140-14$

https://doi.org/10.1097/00003643-200706001$\underline{00503}$

PMID: 12723828
11. Mireskandari, S., \&Makarem, J. (2011). Effect of Rectal Diclofenac and Acetaminophen Alone and in Combination on Postoperative Pain After Cleft Palate Repair in Children. Journal of Craniofacial Surgery, 22(5), 1955-1959. https://doi.org/10.1097/SCS.0b013e31822ea7fd PMID: 21959480

12. Sylaidis, P., \& O'neill, T. (1998). Diclofenac Analgesia following Cleft Palate Surgery. The Cleft Palate-Craniofacial Journal, 35(6). https://doi.org/10.1597/1545-

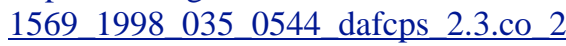
PMID: 9832227

13. Jha, A., Bhardwaj, N., Yaddanapudi, S., Sharma, R., \& Mahajan, J. (2013). A randomized study of surgical site infiltration with bupivacaine or ketamine: EBSCOhost. Paediatric Anaesthesia, 23, 401-406.

https://doi.org/10.1111/pan.12124

PMID: 23445320

14. Takmaz, S. A., Uysal, H. Y., Uysal, A., Kocer, U., Dikmen, B., \&Baltaci, B. (2009). Bilateral extraoral, infraorbital nerve block for postoperative pain relief after cleft lip repair in pediatric patients: A randomized, double-blind controlled study. Annals of Plastic Surgery, 63(1), 59-62. https://doi.org/10.1097/SAP.0b013e3181851b8e

15. Feriani, G., Hatanaka, E., Torloni, M. R., \& da Silva, E. M. (2014). Infraorbital nerve block for postoperative pain following cleft lip repair in children. Cochrane Database of Systematic Reviews, 2014 (5). https://doi.org/10.1002/14651858.CD011131 PMID: 27074283

16. Reena, Bandyopadhyay, K. H., \& Paul, A. (2016). Postoperative analgesia for cleft lip and palate repair in children. Journal of Anaesthesiology Clinical Pharmacology (Vol. 32, Issue 1, pp. 511).

https://doi.org/10.4103/0970-9185.175649

PMID: 27006533 